\title{
BMJ Open Exploring the knowledge, attitudes, practices and lived experiences of frontline health workers in the times of COVID-19 : a qualitative study from Bangladesh
}

To cite: Tune SNBK, Islam BZ, Islam MR, et al. Exploring the knowledge, attitudes, practices and lived experiences of frontline health workers in the times of COVID-19 : a qualitative study from Bangladesh. BMJ Open 2022;12:e051893. doi:10.1136/ bmjopen-2021-051893

- Prepublication history and additional supplemental material for this paper are available online. To view these files, please visit the journal online (http://dx.doi.org/10.1136/ bmjopen-2021-051893).

Received 31 March 2021 Accepted 16 November 2021

Check for updates

(c) Author(s) (or their employer(s)) 2022. Re-use permitted under CC BY-NC. No commercial re-use. See rights and permissions. Published by BMJ.

${ }^{1}$ Centre of Excellence for Health Systems and Universal Health Coverage, BRAC James P Grant School of Public Health, BRAC University, Dhaka, Bangladesh ${ }^{2}$ Poverty, Health and Nutrition Division, International Food Policy Research Institute, Dhaka, Bangladesh

Correspondence to

Samiun Nazrin Bente Kamal

Tune; samiun.tune@bracu.ac.bd

\section{ABSTRACT}

Objective This study explored Frontline Health Workers' (FLWs) knowledge, attitude and practice (KAP) on COVID-19 and their lived experiences, in both their personal and work lives, at the early stage of the pandemic in Bangladesh.

Design, setting and participants This was a qualitative study conducted through telephone interviews in May 2020. A total of 41 FLWs including physicians, nurses, paramedics, community healthcare workers and hospital support staff from 34 public and private facilities of both urban and rural parts of Bangladesh participated in the interview. A purposive sampling technique supplemented by a snowball sampling method was followed to select the participants. The in-depth interviews followed a semistructured interview guide, and we applied the thematic analysis method for the qualitative data analysis.

Findings Except physicians, the FLWs did not receive any institutional training on COVID-19, including its prevention and management, in most instances. Also, they had no training in the use of personal protective equipment (PPE). Their common source of knowledge was the different websites or social media platforms. The FLWs were at risk while delivering services because patients were found to hide histories and not maintaining safety rules, including physical distancing. Moreover, inadequate supply of PPE, fear of getting infected, risk to family members and ostracisation by the neighbours were mentioned to be quite common by them. This situation eventually led to the development of mental stress and anxiety; however, they tried to cope up with this dire situation and attend to the call of humanity.

Conclusion The uncertain work environment during the COVID-19 pandemic simultaneously affected FLWs' physical and emotional health in Bangladesh. However, they showed professional devotion in overcoming such obstacles and continued to deliver essential services. This could be further facilitated by a quick and targeted training package on COVID-19, and the provision of supplies for delivering services with appropriate safety precautions.

\section{Strengths and limitations of this study}

- Our purposive sampling selection tried to reach frontline health workers (FLWs) from all levels (primary to tertiary) of health facilities from different urban and rural areas and also covered all eight divisions of Bangladesh.

- Therefore, the study findings tried to reflect the experiences of FLWs from both the public and private sectors of Bangladesh during the COVID-19 pandemic.

- This study had few limitations as well. As it was a time-bound study and conducted when the country was under lockdown, hence the interviews were carried out over the phone.

- Face-to-face interviews with FLWs could portray the relatively vibrant scenario of the health facilities and emergency services in Bangladesh amidst the newly emerged pandemic.

- Besides, some of the FLWs were not comfortable or were reluctant to talk about COVID-19 pandemicrelated issues over the phone.

\section{BACKGROUND}

Frontline health workers (FLWs) are the physicians, nurses, paramedics, pharmacists, community healthcare workers (CHWs) and other supporting staff who serve in the health sector. $^{1}$ The COVID-19 outbreak at the end of 2019 developed into a pandemic at the beginning of 2020 and became an unforeseen challenge for the health systems the world over as the virus spread explosively, beyond existing capacities of the hospitals and other healthcare facilities, and placing healthcare personnel at high risk of exposure. ${ }^{2}$ Infected or exposed FLWs could also be a source of spreading the infection to patients and their coworkers unknowingly and unintentionally. ${ }^{3}$

Inappropriate knowledge on and unawareness of COVID-19 among the FLWs risk them 


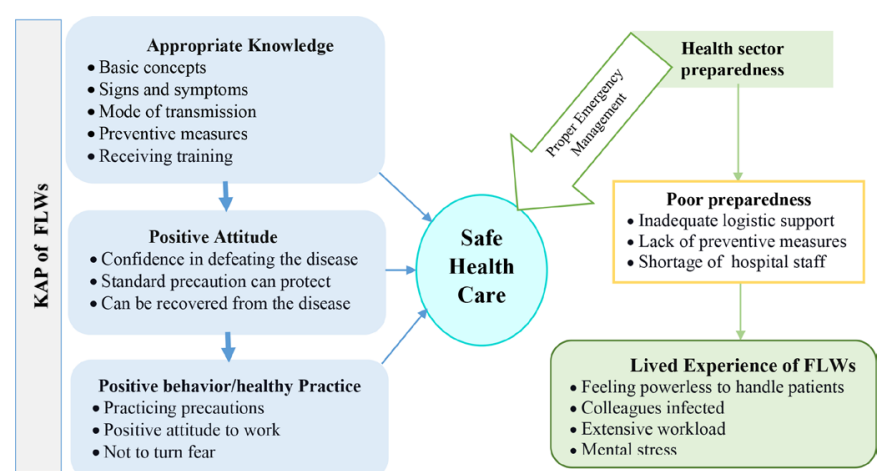

Figure 1 Conceptual framework of the study. ${ }^{34915-18}$ FLW, frontline health worker; KAP, knowledge, attitude and practice.

to a vulnerable situation while handling patients as well as getting infected from patients. ${ }^{4}$ On the other hand, ample knowledge about the disease, a positive attitude and meticulous hygiene practices (as recommended by WHO) vis-à-vis COVID-19 among all levels of FLWs aid in avoiding the cross-infection and deliver services effectively. ${ }^{5}$ Building appropriate knowledge, attitude and practice (KAP) and safeguarding the FLWs is of utmost importance for continuing patient care and maintain healthcare systems functioning during the pandemic. ${ }^{6}$ However, safeguarding the FLWs became a worldwide hurdle during the COVID-19 pandemic due to a low level of awareness and shortage of adequate and appropriate personal protective equipment (PPE), and insufficient testing kits in most countries. ${ }^{67}$ They were not only exposed physically to the virus but also threatened with mental and emotional distress, professional and social stigma, long working hours, exhaustion and environmental violence. ${ }^{7}$ These were common experiences, especially among FLWs in the lower-middle-income countries (LMICs) in South/Southeast Asia and sub-Saharan Africa. ${ }^{8}$ Policymakers and national and international standards bodies, along with the WHO and scientific organisations, played a key role in developing global knowledge and awareness regarding COVID-19 safety issues to ensure proper quality and protection for patients and healthcare providers in this pandemic situation. ${ }^{10}$

Bangladesh, with a high population density, became more vulnerable during the pandemic as the social distance was difficult to maintain and with ${ }^{11}$ poor infection prevention and control mechanisms in hospitals and health facilities. ${ }^{12}$ Bangladesh reported its first physician death on 15 April with a total of 100 physicians and 57 nurses being infected. ${ }^{13}$ As of August 2020, the number of COVID-19 cases among frontline healthcare providers increased to 7296, of which 2531 were doctors; also 73 physicians died of COVID-19. ${ }^{14}$ In view of the global scenario in the early stage of the COVID-19 pandemic, it became imperative to look into the KAP and lived experiences of the FLWs vis-à-vis COVID-19 in Bangladesh in the early stage. Thus, this study aimed to explore the knowledge, attitude, practice and lived experiences of FLWs during the first wave of COVID-19 in Bangladesh.

\section{Conceptual framework}

The conceptual framework (figure 1) for this study was developed based on various literature reviews. Knowledge regarding any disease is essential for establishing prevention beliefs, developing positive attitudes and encouraging positive behaviours. ${ }^{15}$ Proper knowledge of FLWs regarding infectious disease prevention and its management, positive attitude and meticulous hygiene practices are important elements in managing patients, reducing the risk of transmission of infection and providing safe healthcare. ${ }^{491617}$ Oppositely, lack of correct knowledge, as well as poor hospital preparedness such as lack of logistic support and shortage of hospital staff, leads to a delay in identification and diagnosis of the disease, which increases the risk of transmission among colleagues and through them to the communities. ${ }^{3}$ Due to poor hospital preparedness, FLWs face many challenges in their personal and professional lives. ${ }^{17} 18$ High workload, mental stress and feeling helpless while handling patients are the common experiences of different types of FLWs. ${ }^{17} 18$

\section{METHODS}

\section{Study design}

This exploratory qualitative study followed a purposive sampling method supplemented by snowball sampling and involved in-depth interviews with different categories of FLWs from various public and private facilities of Bangladesh.

\section{Study population}

This study population comprised 41 different categories of FLWs including physicians, nurses and midwives, paramedics, CHWs and hospital support staff (table 1). The probable respondents were identified through our various networks.

\section{Study sites}

The samples were collected from 34 institutes of 20 districts of eight divisions (Dhaka, Chittagong, Sylhet, Khulna, Rajshahi, Rangpur, Barisal and Mymensingh) in Bangladesh. The study sites (districts) are indicated in figure 2. We included different tires of public facilities (from primary to tertiary level healthcare facilities) such as medical college hospitals, district hospitals, Upazila Health Complex, Union subcentres, Union Health and Family Welfare Centres, community clinics, and also some private facilities and non-governmental organisations.

\section{Study duration and approach}

Data collection for this time-bound study occurred during 7-19 May 2020, adopting a qualitative approach to elicit relevant information from the respondents. Under the situation of lockdown, data were collected through telephone interviews following a list of talking 
Table 1 Study population

\begin{tabular}{ll}
\hline Type of provider & Designation \\
\hline Physicians & $\begin{array}{l}\text { Medical Officer, Resident Medical } \\
\text { Officer, Emergency Medical Officers, } \\
\text { Consultant }\end{array}$ \\
\hline Nurses/midwives & $\begin{array}{l}\text { Senior Staff Nurse, Nursing Supervisor, } \\
\text { Midwife }\end{array}$ \\
\hline Paramedics & $\begin{array}{l}\text { Subassistant Community Medical } \\
\text { Officer, Medical Technologist, }\end{array}$ \\
Paramedic
\end{tabular}

points; the interview was taken in a conversation mode. This telephone survey method is increasingly being used in qualitative healthcare service research as it allows data to be collected from diverse geographical localities, was time and cost-effective compared with the face-toface interview, better response rate than postal surveys and better completion of information. ${ }^{19}$ We did not use any information sheet to inform research participants; rather we had directly called the FLWs and informed

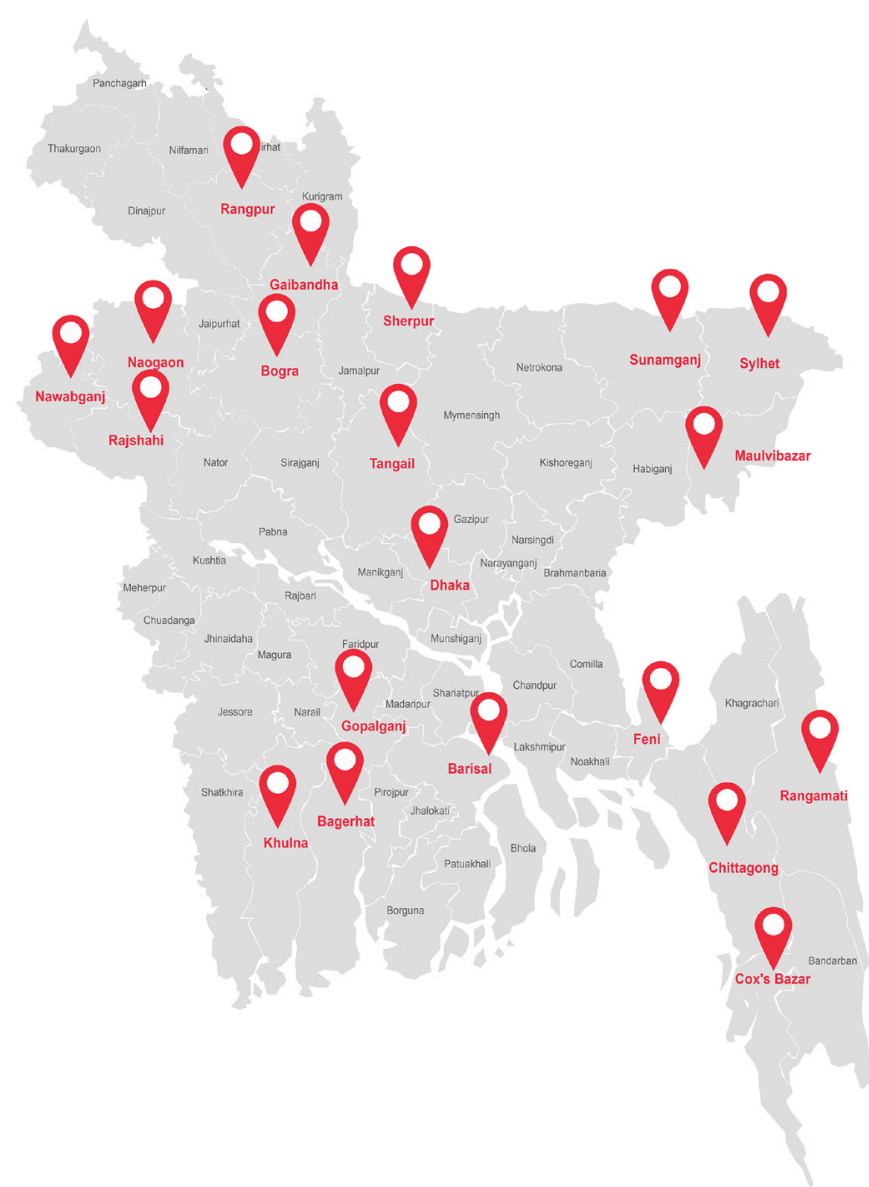

Figure 2 Sites of study sample map from 20 districts of Bangladesh. them about the research topic and the objectives and mentioned the list of talking points. The list of talking points was as follows:

- Knowledge regarding COVID-19.

- Attitude and perception towards COVID-19.

- Practices related to COVID-19.

- Lived experiences (both personal and professional).

\section{Data collection process and tool development}

We used our past networks from various institutes (originating from a past study, approved by the institutional review board) to track down the targeted FLWs as practical and feasible as possible under a lockdown situation and prepared a list of potential participants. As all the participants had already taken part in the earlier study, they were confident in our integrity and gave informed consent to the researchers. The participation in the current study was completely voluntary, and subjects' autonomy to participate or not in the current study was not hampered. The study participants were well aware of our research works during COVID-19 lockdown and did not constitute a vulnerable group. The study tool included queries that did not pose any threat or breach of privacy to the study participants. The list of probable respondents with cell numbers was prepared by the research team. The operational plan for shortlisting the probable respondents and taking appointments and scheduling the interviews was made for maximum use of time.

The interviewers (researchers with experiences in conducting qualitative studies and quick studies on COVID-19) used this list to call on the probable respondents, briefly described the context and purpose of the study, and sought verbal consent. The interview continued for a period of 30-45 min maximum. The interview was meant to be conducted in a conversation mode.

A two-pager tool/semistructured interview guide was developed (online supplemental file 1) and used to guide the interview over phone. This two-pager tool with relevant themes (knowledge, attitude, practice, and experiences) to address the objectives was prepared and it was a kind of checklist for guiding the interview so that no important issue is missed. We asked for approval of recording from participants and then recorded the interviews. In case any participants did not agree to recording, we took notes.

\section{Data analysis}

We performed a thematic analysis of this qualitative data. ${ }^{20}$ Transcriptions were prepared and these were translated in to English. The transcripts were read at least three times by the researchers to become familiar with the contents. Different a priori codes were prepared (online supplemental file 2); some inductive codes emerged from a repeated reading of the transcripts. Then the data were clustered, compared and categorised, and a data display was prepared to identify the pattern. 


\section{Trustworthiness}

The data analysis was carried out in a precise, consistent and exhaustive manner through recording, systematising and disclosing the technique of analysis with enough detail to enable the reader to determine whether the process is credible. Four researchers collected the data and prepared the transcripts. After reading the transcripts from all interviews in detail, the first and second authors (SNBKT and BZI) independently coded the data that were deemed to be relevant to the current study. Disagreements were discussed with the senior author (SMA). The next step was to group related codes into potential themes (SNBKT and BZI). Subsequently, four authors (SNBKT, BZI, MRI and SMA) jointly reviewed the themes to ensure that (1) the codes in each theme were coherent and that (2) the codes in different themes could be distinguished. Finally, the themes were defined and named by two authors (SNBKT and BZI), and a narrative structure with accompanying descriptions was produced by all authors. Moreover, the four key components of data trustworthiness, such as credibility, transferability, dependability and conformability, are ensured by the senior author (SMA). ${ }^{21}$

\section{Patient and public involvement}

Patients and/or the public were not involved in the design, conduct, reporting or dissemination plans of this research.

\section{Findings}

Sociodemographic profile of the FLWs

Of the total $41 \mathrm{FLWs}, 54 \%$ were male, and $46 \%$ were $30-39$ years old. The majority $(71 \%)$ were from public facilities located in the rural areas, and almost one-third (29\%) of the respondents were physicians by training. Fifty-six per cent of the FLWs had more than 5 years of working experience, and about $46 \%$ of the FLWs were responsible for providing services in the inpatient care unit (table 2).

\section{Division-wise distribution of FLWs}

About one-third, $28 \%$ of the FLWs were from the Dhaka division, including the capital (Dhaka) city. The lowest 3\% of participants were selected from Barisal and Mymensingh divisions. Division-wise distribution of the FLWs is illustrated in figure 3 .

Thematic analysis of FLWs' KAP and experience in professional and personal lives during the early days of the COVID-19 pandemic are presented further.

\section{Theme 1: knowledge regarding COVID-19}

Basic concepts, signs, symptoms, mode of transmission and preventive measurements

Physicians from both urban and rural settings were more knowledgeable and well informed regarding the basic concepts of COVID-19 than other FLWs. They were cognisant of the signs, symptoms, mode of transmission of the virus and prevention measures against the virus announced by WHO. They expressed that handwashing with soap/sanitising with alcohol, maintain distancing,

\begin{tabular}{|c|c|}
\hline Characteristics & n (\%) \\
\hline \multicolumn{2}{|l|}{ Sex } \\
\hline Male & $22(54)$ \\
\hline Female & $19(46)$ \\
\hline \multicolumn{2}{|l|}{ Age of FLWs (years) } \\
\hline$<30$ & $9(22)$ \\
\hline $30-<40$ & $19(46)$ \\
\hline $40-<50$ & $7(17)$ \\
\hline$\geq 50$ & $6(15)$ \\
\hline \multicolumn{2}{|l|}{ Type of facility } \\
\hline Public facility in urban area $(\mathrm{MCH}, \mathrm{DH})$ & $7(17)$ \\
\hline $\begin{array}{l}\text { Public facility in rural area (UpHC, USC, } \\
\text { UHFWC) }\end{array}$ & $29(71)$ \\
\hline For profit private facility in urban area & $2(5)$ \\
\hline $\begin{array}{l}\text { Not-for-profit private facility (NGOs) in urban } \\
\text { area }\end{array}$ & $3(7)$ \\
\hline \multicolumn{2}{|l|}{ Type of FLWs } \\
\hline Physicians & $12(29)$ \\
\hline Nurses/midwives & $11(27)$ \\
\hline Paramedics & $7(17)$ \\
\hline $\mathrm{CHWs}$ & $4(10)$ \\
\hline Support staff & $7(17)$ \\
\hline \multicolumn{2}{|l|}{ Years of experience } \\
\hline$<1$ & $8(20)$ \\
\hline $1-5$ & $10(24)$ \\
\hline$>5$ & $23(56)$ \\
\hline \multicolumn{2}{|l|}{ Place of duty } \\
\hline IPD & $19(46)$ \\
\hline OPD & $4(10)$ \\
\hline Both OPD and IPD & $3(7)$ \\
\hline Emergency & $5(12)$ \\
\hline Both OPD and emergency & $8(20)$ \\
\hline Lab & $2(5)$ \\
\hline
\end{tabular}

$\mathrm{CHW}$, community healthcare worker; $\mathrm{DH}$, disctrict hospital; FLW, frontline health workers; IPD, indoor patient department; $\mathrm{MCH}$, medical college hospital; NGO, non-governmental organisation; OPD, outdoor patient department; UHFWC, Union Health and Family Welfare Centre; UpHC, Upazila Health Complex; USC, Union subcentre.

using masks, covering the mouth while sneezing and appropriate use of PPE in the hospital settings were the standard preventive measures for the disease.

Physicians are learning about the disease. Its sign, symptoms, prevention measures are important to know providing the treatment in this pandemic situation. (Female physician)

Mixed knowledge was observed among nurses, paramedics and CHWs (rural/root level FLWs). Some of them 
FLWs accross the eight divisions

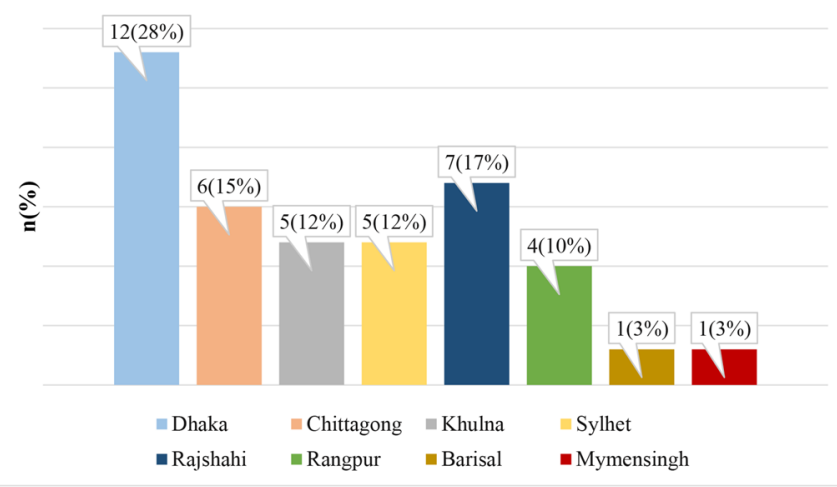

Figure 3. Division-wise selection of FLWs

Figure 3 Division-wise selection of FLWs. FLW, frontline health worker.

were not acquainted with the prevention measurements of COVID-19, as one of them said

There is no supply of hand wash in our facility, we wash our hands using soap. I have no idea whether the soap can kill this deadly virus. (Female, FWV)

The support staff was the confusing workforce among all in terms of knowledge related to COVID-19. They lacked knowledge of its transmission or prevention measurements. One of the word boy from a rural facility expressed:

I have heard that fever is the symptom of this disease, but I don't know how does the virus transmit or what are the actual preventive measures (Male, ward boy $(\mathrm{WB})$ )

\section{Sources of knowledge and training on COVID-19}

Urban physicians underwent formal training on COVID-19 prevention and its management from the Director-General of Health Services (DGHS) and the Institute of Epidemiology Disease Control and Research, and were self-trained following online platforms like the WHO or national guidelines for DGHS websites. On the other hand, the rural providers could not undergo any institutional training due to the sudden lockdown in the country. Nurses had received training on COVID-19 management from their respective facility or authority. Physicians and nurses who underwent the training had learnt the infection prevention, control, triage and screening of COVID-19 in the training session, which facilitated them to improve their knowledge regarding the mysterious virus. A physician said,

I am the only person in this facility who received training on COVID-19 from IEDCR. I had to go to Dhaka for the training. Due to sudden lockdown, other staff of our facility could not receive the training. (Male physician)

Unfortunately, the other FLWs like subassistant community medical officer (SACMOs), medical technologists,
Family Welfare Visitors (FWVs) and WBs did get any opportunity to receive formal training. They received simply verbal instruction from physicians or other staff of their respective facilities. Social media was found to be the common source for the rest of the FLWs. One of the community level healthcare providers expressed:

I have not received any formal training, however, I have seen a video uploaded by our SACMO on a Facebook group, where I have learned how to manage the patients infected with the coronavirus. (Female, FWV)

PPE training, correct methods for donning and doffing PPE Similar to basic training on COVID-19, the FLWs did not undergo any training approaching the proper and effective usage of PPE. The physicians acquired the least ideas of PPE use while undergoing training on COVID-19 patient management from different organisations. They reported that the donning, doffing and discarding of PPE were demonstrated in the training. Also, a separate session and practical demonstration on how to use and discard PPE was included in the training session. Others received virtual training on the use of PPE from the WHO or other institutional websites, social media and YouTube channels. One of the physicians from an urban facility articulated:

However, I did not receive any formal training from my organisation on PPE but I have managed to learn all these from WHO guidelines and national guidelines. (Male physician)

FLWs posted at rural stations were the ignored ones in case of receiving training on PPE too. Only verbal instruction from the hospital senior was provided to them in many cases. Support staff from a rural facility uttered:

We have not received any training on PPE yet. Our higher officials just told us how to deal with a suspected case, and how to wear and dispose of the PPE... .... but a proper training would make us more confident on providing services. (Male, WB)

All levels of FLWs expressed that proper training could guide them in handling patients carefully and in providing treatment confidently. Some of the providers were not convinced with the information provided by some internet sources or confused about the authenticity of the information. Physicians and nurses preferred authentic online sources of information regarding emerging diseases including the current pandemic, whereas the communitylevel staff prefer hands-on training over internet sources.

\section{Theme 2: attitude towards COVID-19}

Attitude towards preventive measures and willingness to work during the COVID-19 era

The physicians and nurses believed that standard precautions could protect them from the risks of COVID19. Other FLWs showed a mixed attitude towards the 
preventive measurements. They perceived that the disease was preventable or curable. Yet, deeming the disease was not curable was found among them as well. One of the nurses from an urban facility confidently expressed:

If we use appropriate PPE and follow the other preventative measurements like handwashing practice, maintaining social distances inside and outside the hospital settings, I believe that we would be safe from COVID-19. (Female nurse)

The FLWs expressed their courage, willingness and dedication to work during this terrible pandemic. They uttered they were ready to face any of the challenges and would continue fighting against the virus. A rural provider said,

Whatever happened to us, we have nothing to do.... we will provide services to the people until we die... it's our duty.... We are the caregivers, we can't deny our duties neither can leave the job. (Male SACMO)

\section{Fear of becoming infected, fear of death}

The FLWs although showed their courage and determination to perform their duties perfectly in this pandemic, but expressing fear of getting infected or dying due to COVID-19 infection was found among them too. The paramedics, community healthcare providers and support staff showed a negative attitude towards the viral infection and were panicked about getting infected. Perception of long sufferings and death due to the virus was commonly found among them. All levels of FLWs assumed that the number of COVID-19 cases was increasing and would continue to increase in the upcoming days. They also believed that anyone could be infected regardless of age, sex and location in the country. Moreover, according to the FLWs, the infection and mortality rate was higher among FLWs than among common people. Providers expressed:

Anyone can be infected or dies of this virus... virus doesn't know who is a doctor or who is not...so I am not out of danger too. (Female physician)

As I directly handle the samples, probably I have more chances of getting infected, many people are getting infected and dying in front of my eyes, no treatment is known to recover from covid-19, so no exception will happen to me, too....if I get infected, probably I will die as well. (Male medical technologist)

\section{Theme 3: practices related to he COVID-19 outbreak}

Regularly and strictly following all the preventive measures, for example, washing/sanitising hands frequently, using masks, maintain distancing from their colleagues and patients, carefully removing PPE, managing or purchasing own PPE, willingness to participate in COVID-19-related training to keep them updated on the viral infection, etc., prevailed among the physicians and nurses/midwives. A provider from the urban facility said,
I am trying to manage my PPE by myself, always trying to be aware of the virus and following the necessary measurements like maintaining distancing from people, washing hands frequently, etc. to prevent myself.... (Male physician)

On the other hand, the rural providers or community level staff stated that because of their very close interactions with community people, they were unable to maintain the distancing with them even inside the hospital settings. Patients visited facilities without wearing masks, wanted to shake their hands with providers and were not aware of washing their hands. The FLW from a rural facility sadly explained:

The rural people do not like maintaining the distance that we keep with them when they visit us ... They want us to shake our hands with them, we can't always avoid them neither can make them realise the situation (Male community healthcare provider)

Managing patients following protocol, coping mechanism Apart from using personally purchased PPEs, urban FLWs were dealing with all cases of suspected patients quite according to the protocol (triage and screening). Private facilities in urban areas follow the more structured and advanced protocol as they usually had the option of proper triage and screening. One of the providers from private sector vividly described:

We have triage and screening protocol... we try to isolate the COVID-19 suspected patient at emergency... there is a specific corner in our hospital, we try to treat them there. If those corona dedicated rooms or intensive care unit (ICU) is not vacant, we refer them to another hospital. (Male physician)

At the grassroot level, the FLWs were aware of ways of dealing with patients during the pandemic crisis. Although triage was not possible there, they asked the patients whether they had any symptoms of COVID-19 or not. Counselling the patients also came up as a strategy to deal with the suspected cases. One of the rural FLWs thus expressed:

Nowadays we try to handle every patient equally, we consider them as they are already infected and counsel them accordingly. (Female Health Assistant (HA)

\section{Theme 4: lived experiences of the FLWs in professional and personal lives}

Shortage of personal protective equipment, lack of supply from the facility

The shortage of proper protective equipment was the biggest challenge faced by FLWs at all levels. It was hindering their physical and familial situation as well as hampering their mental health at both personal and professional levels. The quality of PPE was a matter of concern, too. They assumed the PPEs were not protecting them properly since many of their colleagues 
were frequently getting infected with the virus. Moreover, they had to reuse PPEs due to the shortage of supplies from the facility. Even after requesting the local authorities like assistant commissioners/Upazila Nirbahi officers, many of them could not manage to get any PPE. In rural areas, PPE was hardly available. Pharmaceutical companies or civil society organisations donated PPEs to a limited number of FLWs and which were administered once in a facility. Considering the risk scenario, they had to purchase their PPEs out of their self-awareness. Purchasing PPE on a regular basis on their own was also challenging for them on account of the high market price during the pandemic. FLWs vividly expressed:

We are facing trouble because of not getting proper and adequate PPE. PPE provided by the authority is basically for one-time use. As we are reusing it, eventually we can be infected.... (Male physician)

I have received one set of PPE once from the facility...I am reusing the gown daily...but I had to buy some N95 masks myself. (Female midwife)

The rural FLWs were facing trouble because of the shortage or no supply of hand soap or sanitiser inside the facilities. Also, the KN95 masks and gloves were rare in rural markets.

We are not getting enough PPE, hand wash, and hand sanitizer. When patients come to us, we cannot tell them to wash their hands first then enter the facility. Because we don't have running water outside the center. Tube well is also far from here. (Female, FWV)

\section{Patients lacked awareness of COVID-19, risking FLWs' lives}

The FLWs of all levels expressed that the patients lacked knowledge of COVID-19 and thus they did not follow any precautions for COVID-19. The FLWs face hurdles during handling, such ignorant patients in the early days of the COVID-19 pandemic. Wearing masks and keeping social distances were not maintained by patients. The scenario was even worst in the rural community. The FLWs stated that patients' unawareness and ignorance towards COVID-19 precautions eventually made their lives extremely vulnerable and they were getting infected within a short period due to such ignorance of community people. Some illustrative quotes by the FLWs are as follows:

People wander around keeping the masks in their pockets. Even if they come to the hospital they don't use masks. If the whole family comes to the hospital, one of them wears a mask and the others don't. (Female physician)

As they don't know about this pandemic, they don't follow any preventive measurement and behaves like the virus is nothing serious.... (Male SACMO)
Patients scared of being isolated and socially stigmatised, FLWs facing trouble

Hiding histories among the suspected patients were among the rural community, mentioned by the FLWs. The urban patients had certain misconceptions regarding the disease as well. While the people detected with COVID-19 were positive, they were fearful of being isolated, socially stigmatised and frightened of not getting treatment from the facilities. The FLWs also expressed that the people tend to hide history/symptoms from fear/phobia about being quarantined or the term 'quarantine'. Also, neglect by society and neighbours was the prime concern for the community people. Besides, they assumed that police and local authorities will lock them. Eventually, the situation made all levels of FLWs scared to provide treatment to the suspected cases at the beginning of the uncertain times of the COVID-19 pandemic. One of the FLWs from an urban facility expressed:

They (covid-19 suspected or patients) have a fear of not getting proper treatment and social harassment if they express their histories... as they are hiding their histories, we are eventually at risk. (Male physician)

The FLWs from rural facilities said,

Corona suspected people are neglected by society. Villagers think this kind of people is not good human beings...so they humiliate the infected people. (Female nurse)

They don't have enough idea about quarantine, again they think they might be harassed by the administration or the villagers if they reveal any sign or symptoms. (Male SACMO)

\section{FLWs' mental health fallout, shortage of staff and high workload}

Anxiety and panic became common among FLWs at the beginning of the COVID-19 pandemic. The major threat to the mental health of these FLWs was the fear for their families' safety as they were frequently exposed and had to return home at the end of the day. The FLWs had to serve for a 24-hour-long hospital duty wearing the same PPE. They did not discard it during the day; rather, they tried to preserve the PPE for another day. Sometimes they could not even go to the washroom because of the deficit of PPE. They were worried as this consequence might end up with other health issues. Moreover, they experienced a shortage of workforce in the facilities. Consequently, there was high workload than the normal days during the pandemic state. No policy of $7 / 14$ quarantine was followed accordingly. Most of them did not get any separate accommodation after COVID-19 duty. They FLWs were frightened and worried about their family members' health and safety issues. One of them stated,

I am not frightened if I get infected, I am scared of what would happen if my family get infected... I would not forgive myself and such though are making me mentally upset. (Female physician) 


\section{Socially ostracised}

The FLWs were neglected and ostracised by neighbours. The community people deeming their speculations of being infected with COVID-19 through the FLWs. Both the urban and rural FLWs experienced remarkable indifference from society. Neighbours or homeowners of the physicians residing in urban areas at times refused to allow them to return home after duty. The rural FLWs equally were humiliated by the local shopkeepers who denied to vend their products to them. Consequently, emotional distress and negligence by society made their lives more depressing, as they expressed:

Homeowner and neighbours do not want us to go back to home after hospital duty ... they are concerned about their health issues and considering their safety, sometimes the homeowner even locked the main gate, so that we cannot enter the house. (Male physician)

I went to buy food in the local market, the vendor misbehaved with me and directly told me not to visit his shop anymore....I felt so devastated and couldn't decide where to go to purchase the essential goods at midnight. (Male SACMO)

\section{DISCUSSION}

This study was done to explore the situation of FLWs regarding KAP on COVID-19, its prevention and management, and lived experiences of the pandemic at personal and familial levels. A phone interview approach was adopted to elicit relevant information from the targeted group of FLWs.

\section{FLWs KAP regarding COVID-19}

Findings reveal that most FLWs did not or could not receive any formal training on COVID-19 regarding its prevention and treatment, as well as on the use of PPE except for a few physicians and nurses. Most of them, however, managed to learn the basic principle from relevant websites, social media or briefing from colleagues. Many of them were not convinced; others were confused about the authenticity of the information provided by different sources and concluded that formal institutional training would benefit them in managing patients wisely and more confidently amidst such a pandemic.

Authentic COVID-19 online resources played an important role in self-educating some FLWs, especially physicians and nurses in the absence of institutional training at the beginning of the pandemic. Also, proper use of PPE ('donning and doffing') was learnt from these online materials. Our finding tallies with what was observed in Uganda as well. ${ }^{4}$ Another study conducted among the healthcare workers in a South Eastern Nigerian state also revealed that the major sources of information among them $(99.77 \%)$ were the internet, social media and other electronic media. ${ }^{17}$ These findings indicate that COVID-19 websites and social platforms should circulate reliable and valid information as these may be used as a stopgap measure when formal training could not be organised. However, paramedics and community-level health workers expressed their preference for hands-on training on emerging diseases like COVID-19. Therefore, considering the level of FLWs and their demands, we found that the kind of training and delivery of information should be prioritised.

\section{FLWs' lived experiences during the early days of COVID-19 pandemic}

The FLWs at all levels went through several personal and professional challenges such as shortage of the appropriate and the adequate number of PPE, masks and disinfectants. Most of them were emotionally distressed during the COVID-19 pandemic because of fear of being infected or getting family members infected. This was compounded by a high workload, lack of adequate rest to regenerate and an absence of a 7/14 quarantine policy, and ostracisation by the society. Besides, FLWs faced hurdles discharging duties in an unsafe environment as patients were hiding the history of exposure due to social stigma, not maintaining social distance and being unaware of the risks from COVID-19. Although FLWs felt panicked, fearful, anxious and distressed, they did not lag behind in response to the call of duty.

It appeared that, in addition to the shortage of PPE supplied, our study participants were also doubtful about its quality. A study conducted in a tertiary-level hospital in Bangladesh also found that more than $40 \%$ of hospital staff had to reuse the PPEs, and only $10 \%$ of them had training on PPE. ${ }^{22}$ Similar observations were made among Flemish general practitioners, ${ }^{23}$ and health workers of Pakistan ${ }^{24}$ who had a shortage of PPE during the early days of the epidemic. Not only PPE but also masks/N95 respirators, gloves, face shields or goggles, and full-suit/gown were also short in supply in Pakistan. ${ }^{25}$ That study also reported that the reuse of PPE became common among physicians, and many of them even were forced to continue their hospital duties without wearing PPE. Interestingly, the comparative study revealed that physicians in the USA had comparatively high access to PPE, but the percentage of reuse was even higher among them compare to Pakistan since US physicians rarely purchased PPEs themselves. ${ }^{25}$ The shortage of supply of PPEs is noticeable in LMICs; therefore, the FLWs faced more troubles compared with the health providers of high-income countries.

Mental and emotional distress and depression among the FLWs were notable worldwide during COVID$19^{26}$ or any other pandemic like Severe Acute Respiratory Syndrome (SARS) ${ }^{27} 28$ or Middle East Respiratory Syndrome (MERS) ${ }^{29}$ It is commendable to note that the FLWs in Bangladesh continued to discharge their duties amidst this disastrous situation. A similar situation was also observed among the physicians and nurses serving in COVID-19 designated hospitals in China during this global crisis. ${ }^{26}$ 


\section{Recommendations}

The early stage of the COVID-19 pandemic was difficult for FLWs at all levels for delivering services without proper knowledge or training on COVID-19 and insufficient personal safety measures. Also, lack of awareness among patients was regarded as a risk factor for the health and lives of FLWs. Based on the study findings, we suggest some recommendations which might ease up FLWs' personal and professional lives during a pandemic. First, the authority should organise formal training on the disease and its prevention and management at the very beginning of the outbreak so that FLWs can gain first-hand knowledge on the disease and provide services with confidence and compassion. Second, ensuring the supply of an adequate amount of appropriate safety gear to all levels of FLWs is highly recommended to make their work-life safe. Third, building awareness among community people on emerging diseases with epidemic potential like COVID-19 through a comprehensive information, education and communication campaign will go a long way in preparing the people and the health systems for an inclusive and effective response now, and also in the future.

\section{CONCLUSION}

The drastic work environment throughout the COVID-19 pandemic drained FLWs physically and mentally. Yet, FLWs in Bangladesh were trying to prove their resilience, vigour and dedication of professional life to overcome such difficulties. Immense support should be provided by the authority to safeguard the protection of FLWs. Intensive and regular training on COVID-19 and its management would be fruitful to enhance the preparedness and efficiency to overcome this crisis moment.

Acknowledgements The study team expresses its gratitude to Bangladesh Health Watch and BRAC James P Grand school of Public Health, BRAC University for giving the opportunity and supporting to conduct the study during the COVID-19 lockdown situation in the country.

Contributors SNBKT, BZI, MRI, and SMA conceived the study. SNBKT, BZI, and ZT collected the qualitative data over the phone. SNBKT and BZI performed the data analysis. SNBKT drafted the first manuscript. SMA reviewed and provided intellectual inputs on the draft and contributed to the writing of the manuscript. SNBKT revised the manuscript based on SMA's inputs. All authors reviewed and approved the final version of the manuscript.

Funding The authors have not declared a specific grant for this research from any funding agency in the public, commercial or not-for-profit sectors.

Map disclaimer The inclusion of any map (including the depiction of any boundaries therein), or of any geographical or locational reference, does not imply the expression of any opinion whatsoever on the part of BMJ concerning the legal status of any country, territory, jurisdiction or area or of its authorities. Any such expression remains solely that of the relevant source and is not endorsed by BMJ. Maps are provided without any warranty of any kind, either express or implied.

\section{Competing interests None declared.}

Patient consent for publication Not applicable.

Ethics approval Ethical approval was obtained from the institutional review board (IRB) of BRAC James P Grant School of Public Health BRAC University, Dhaka, Bangladesh (IRB Reference No. 2020-011-IR). Informed verbal consent was obtained from each participant before initiating conversations over the phone and after collection of data; the names and numbers were removed; and data were analysed anonymously. No invasive procedure was used. Data were collected anonymously; confidentiality of data was maintained at all stages of the study, and data were used only for research purposes.

Provenance and peer review Not commissioned; externally peer reviewed.

Data availability statement Data are available upon reasonable request.

Supplemental material This content has been supplied by the author(s). It has not been vetted by BMJ Publishing Group Limited (BMJ) and may not have been peer-reviewed. Any opinions or recommendations discussed are solely those of the author(s) and are not endorsed by BMJ. BMJ disclaims all liability and responsibility arising from any reliance placed on the content. Where the content includes any translated material, BMJ does not warrant the accuracy and reliability of the translations (including but not limited to local regulations, clinical guidelines, terminology, drug names and drug dosages), and is not responsible for any error and/or omissions arising from translation and adaptation or otherwise.

Open access This is an open access article distributed in accordance with the Creative Commons Attribution Non Commercial (CC BY-NC 4.0) license, which permits others to distribute, remix, adapt, build upon this work non-commercially, and license their derivative works on different terms, provided the original work is properly cited, appropriate credit is given, any changes made indicated, and the use is non-commercial. See: http://creativecommons.org/licenses/by-nc/4.0/.

\section{ORCID iDs}

Samiun Nazrin Bente Kamal Tune http://orcid.org/0000-0003-0308-2817

Bushra Zarin Islam http://orcid.org/0000-0002-9988-7558

Mir Raihanul Islam http://orcid.org/0000-0003-2125-2218

Zarin Tasnim http://orcid.org/0000-0001-8740-6836

Syed Masud Ahmed http://orcid.org/0000-0001-5032-7181

\section{REFERENCES}

1 World Health Organization. Health workers: a global profile, 2006. Available: https://www.who.int/whr/2006/06_chap1_en.pdf [Accessed 09 Aug 2020].

2 Park SH. Personal protective equipment for healthcare workers during the COVID-19 pandemic. Infect Chemother 2020;52:165.

3 Malik UR, Atif N, Hashmi FK, et al. Knowledge, attitude, and practices of healthcare professionals on COVID-19 and risk assessment to prevent the epidemic spread: a multicenter crosssectional study from Punjab, Pakistan. Int J Environ Res Public Health 2020;17:6395.

4 Olum R, Chekwech G, Wekha G, et al. Coronavirus Disease-2019: knowledge, attitude, and practices of health care workers at Makerere university teaching hospitals, Uganda. Front Public Health 2020;8:181.

5 Wu Z, McGoogan JM. Characteristics of and important lessons from the coronavirus disease 2019 (COVID-19) outbreak in China: summary of a report of 72314 cases from the Chinese center for disease control and prevention. JAMA 2020;323:1239-42.

6 Bandyopadhyay S, Baticulon RE, Kadhum M, et al. Infection and mortality of healthcare workers worldwide from COVID-19: a systematic review. BMJ Glob Health 2020;5:e003097.

7 Gan WH, Lim JW, Koh D. Preventing intra-hospital infection and transmission of coronavirus disease 2019 in health-care workers. Saf Health Work 2020;11:241-3.

8 Wang J, Zhou M, Liu F. Reasons for healthcare workers becoming infected with novel coronavirus disease 2019 (COVID-19) in China. $J$ Hosp Infect 2020;105:100-1.

9 Abdel Wahed WY, Hefzy EM, Ahmed MI, et al. Assessment of knowledge, attitudes, and perception of health care workers regarding COVID-19, a cross-sectional study from Egypt. J Community Health 2020;45:1242-51.

10 Pecchia L, Piaggio D, Maccaro A, et al. The inadequacy of regulatory frameworks in time of crisis and in low-resource settings: personal protective equipment and COVID-19. Health Technol 2020;10:1375-83.

11 Kar SK, Oyetunji TP, Prakash AJ, et al. Mental health research in the lower-middle-income countries of Africa and Asia during the COVID-19 pandemic: a scoping review. Neurol Psychiatry Brain Res 2020;38:54-64.

12 Hassan MZ, Monjur MR, Styczynski AR, et al. Protecting frontline healthcare workers should be the top priority in low-resource health systems: Bangladesh and COVID-19. Infect Control Hosp Epidemiol 2021;42:121-2. 
13 Sakib SM. Bangladesh: low COVID-19 testing rate raises concerns, 2020. Available: https://www.aa.com.tr/en/asia-pacific/bangladeshlow-covid-19-testing-rate-raises-concerns/1810132 [Accessed 19 Nov 2020].

14 The Daily Star. First coronavirus cases confirmed, 2020. Available: https://www.tbsnews.net/coronavirus-chronicle/covid-19bangladesh/so-far-73-doctors-die-covid-19-bangladesh-117301 [Accessed 30 Nov 2020].

15 McEachan R, Taylor N, Harrison R, et al. Meta-analysis of the reasoned action approach (RAA) to understanding health behaviors. Ann Behav Med 2016;50:592-612.

16 Zhang M, Zhou M, Tang F, et al. Knowledge, attitude, and practice regarding COVID-19 among healthcare workers in Henan, China. $J$ Hosp Infect 2020;105:183-7.

17 Mbachu CNP, Azubuike CM-C, Mbachu II, et al. COVID-19 infection: knowledge, attitude, practices, and impact among healthcare workers in a south-eastern Nigerian state. J Infect Dev Ctries 2020;14:943-52.

18 Chen P, Lei J, Chen F, et al. Experiences and perceptions risk of health-care workers from coronavirus: a protocol for systematic review. Medicine 2020;99:e20308.

19 Smith EM. Telephone interviewing in healthcare research: a summary of the evidence. Nurse Res 2005;12:32-41.

20 Braun V, Clarke V. Using thematic analysis in psychology. Qual Res Psychol 2006;3:77-101.

21 Elo S, Kääriäinen M, Kanste O. Qualitative content analysis: a focus on trustworthiness. SAGE open 2014;5:2158244014522633.

22 Yasmin R, Parveen R, Azad NA, Al Azad N, et al. Corona virus infection among healthcare workers in a COVID dedicated tertiary care hospital in Dhaka, Bangladesh. J. Bangladesh Coll. Phys. 2020;9:43-9.

23 Verhoeven V, Tsakitzidis G, Philips H, et al. Impact of the COVID-19 pandemic on the core functions of primary care: will the cure be worse than the disease? A qualitative interview study in Flemish GPs. BMJ Open 2020;10:e039674.

24 Hakim M, Khattak FA, Muhammad S, et al. Access and use experience of personal protective equipment among frontline healthcare workers in Pakistan during the COVID-19 emergency: a cross-sectional study. Health Secur 2021;19:2:140-9.

25 Ahmed J, Malik F, Bin Arif T, Arif TB, et al. Availability of personal protective equipment (PPE) among US and Pakistani doctors in COVID-19 pandemic. Cureus 2020;12:e8550.

26 Liu Q, Luo D, Haase JE, et al. The experiences of health-care providers during the COVID-19 crisis in China: a qualitative study. Lancet Glob Health 2020;8:e790-8.

27 Maunder R, Hunter J, Vincent L, et al. The immediate psychological and occupational impact of the 2003 SARS outbreak in a teaching hospital. CMAJ 2003;168:1245-51.

28 Marjanovic Z, Greenglass ER, Coffey S. The relevance of psychosocial variables and working conditions in predicting nurses' coping strategies during the SARS crisis: an online questionnaire survey. Int J Nurs Stud 2007;44:991-8.

29 Lee SM, Kang WS, Cho A-R, et al. Psychological impact of the 2015 MERS outbreak on hospital workers and quarantined hemodialysis patients. Compr Psychiatry 2018;87:123-7. 